This paper was presented at the N.Z.P.C.I. 12 th Annual

Conference, 1976

\title{
ASPECTS OF THE \\ FIP RECOMMENDATIONS FOR DESIGN OF ASEISMIC PRESTRESSED CONCRETE STRUCTURES
}

\author{
S. Inomata*
}

\section{BASIC CONCEPT OF ASEISMIC DESIGN}

It is generally accepted that a structure should be designed in such a way that structural damage causing significant loss of prestress reducing the serviceability for normal use should be prevented in moderate earthquakes, and that collapse or serious damage should be avoided in severe earthquakes. Little or no post-elastic deflection is desirable during moderate earthquakes, while a considerable amount of controlled postelastic behaviour can generally be accepted during severe earthquakes.

Following facts should be emphasised to make the structures to be able to survive major earthquakes: (a) the structures have sufficient margin of strength capacities above the strength estimated as necessary, or (b) they are capable of developing large post-elastic deformations, not exceeding their deformation capacities, thus, limiting their response acceleration below a certain value, and (c) they have the above two characteristics at the same time.

In the light of the above consideration, the design acceleration should be increased for the less ductile structures, in order to give them the sufficient margin of strength capacities.

Fig. 1 shows the several relationships between resisting horizontal force and aisplacement for various typical structures, designed on the basis of $0.2 \mathrm{~g}$ acceleration. A structure provided with many shear walls, will have great strength capacities, whatever the design acceleration would be, in spite of considerable cracking in the shear walls (Type I). A frame structure reinforced with a smaller amount of shear wall or a rigid frame structure with greater rigidity, can be included in the second category (Type II). If appropriate consideration was paid to the necessary ductility of the beams and columns, the frame structure itself can survive the earthquakes, regardless of the possible failure of the shear walls for the former case and the rigid frame does not yield regardless of cracking due to bending and shear for the latter case. A ductile frame structure can survive the major earthquakes developing large plastic deformation (Type III).

If the reduction in the deformation capacity could occur in the structure due to possible constructional discrepancies, the collapse of the structure would be expected, for all the types of structure, even if the resisting strength capacity is greater than the design value.

\footnotetext{
* Chairman of FIP Seismic Commission, F.K.K., Japan.
}

Considering the structural characteristics of the structures to be designed, appropriate strength capacity as well as deformation capacity should be given to the structures.

\section{FAILURE MODE AND DESIGN PRINCIPLE}

There are two principal failure modes of the structures subjected to the severe earthquakes: (a) flexural yield, (b) shear failure. The characteristics of the structures can be represented in Fig. 2, according to the relations between the strength capacities of the structures and their responses to the earthquake motions. In Fig. 2 abscissa and ordinate represent the flexural capacity and the shear capacity of the structure, respectively. These capacities are expressed as base shear coefficients under which the structure attains its flexural capacity or shear capacity. In region situated above the line $O A$, the flexural failure mode can be expected, while in the region below the line $O A$, the shear failure mode of the structure can be.

On the assumption of an appropriate non-elastic relationships between the applied force and the deformation of the structure, it is possible to make clear whether the structure can resist the severe earthquake with its strength capacity or with its post-elastic deformations, by comparing the strength capacity and the elastic response. The elastic response of the structure can be expressed as the base shear coefficient EL-C. If the flexural and shear capacity of the structure is greater than EL-C, the induced horizontal forces do not exceed the strength capacity during the earthquake, and the design principle can be laid down on the strength capacity. In the region being situated inside of $\mathrm{BCD}$, the structure can be designed on the basis of the strength capacity. while in the region situated outside of $B C D$ the structures should be designed on the assumption that they develop plastic deformations during the earthquakes. Shear failures are non-ductile and must be avoided in the aseismic design of the structures, and therefore the region situated inside of $O C D$ should be excluded from the design principle based on the deformation capacity. Although the design principle based on the deformation capacity can be allowed for the aseismic design of the prestressed concrete structures, too large deformations may not be permitted from a practical point of view. The postelastic response deformations of the structures may depend upon the shape of skelton curve, damping, natural vibration periods and earthquake motions. The displacement ductility factor as a measure of the ductility of structures could be 
limited below a certain value (say less than 4 depending upon the expected damages), if the structures were designed having a certain surplus of the strength capacity corresponding to the intensity of the design earthquake. For this reason, the minimum base shear coefficient, MIN-C, was introduced into Fig. 2 .

Finally, three zones in which the aseismic design can be carried out, are designated as $A, B$ and $C$. In the zones $A$ and $B$, the design of the structures can be carried out on the basis of the strength capacity, but the zone $B$ is less favourable because of the non-ductile shear failure mode. Although the strength capacity is less than the elastic response actions, in the zone $C$, the structures are capable of developing large post-elastic deformations thus the response actions are kept below the strength capacity of the structures. In this case the deformation capacity of the structures should be carefully investigated. The premature shear failure should be avoided in the zone $\mathrm{C}$. The possible overstrength for the moment capacity should be taken into account in the design of shear capacity, therefore the zone $C$ should be bounded by a line $\mathrm{CD}$ instead of $\mathrm{EC}$, as shown in $\mathrm{Fig} .2$.

\section{SHEAR CAPACITY}

The ultimate shear capacity should be always greater than the ultimate flexural capacity. The design shear force should be calculated for the state when plastic hinges form in the structure under the action of earthquake and permanent loads as well as variable loads, if any, and allowance should be made for possible overstrength of the materials leading to greater flexural capacities than those calculated on the basis of the characteristic strengths of the materials. To estimate the possible increase of the flexural capacity due to the overstrength of the materials, a simple calculation was carried out on a rectangular section with prestressing steel near the extreme tension fiber.

The term characteristic strength means that the value of the strength of the materials below which not more than 5 o of the test results fall and the probable maximum strength of the materials could be defined as that the value of their strength abcve which not more than $5 \%$ of the test results exceed. The coefficients of deviation for prestressing steel and cast-in-place concrete can be assumed to be equal to $2 \%$ and $10 \%$, respectively. Therefore the relationships between the probable maximum strength and the characteristic strength can be given as :

$$
\begin{aligned}
& \text { prestressing steel...probable max. }=1.07 \times \\
& \text { characteristic } \\
& \text { concrete........... probable max. }=1.39 \times \\
& \text { characteristic }
\end{aligned}
$$

The effect of overstrength in the strengths of the materials on the flexural capacities was checked.

The result shows that the maximum increase of $12 \%$ for the ultimate flexural capacity can be expected in case the overstrengths of the both materials occur simultaneously, having the probability of 1 in 400 . From the above consideration, it may be concluded that the plastic hinge moments should be determined considering the possible overstrengths of the materials and these enhanced plastic moments could be taken as much as 1.15 times the flexural capacities obtained on the basis of the characteristic strengths of the materials.

\section{FLEXURAL DUCTILITY}

Once post-elastic deformation has commenced in a frame, the deformations concentrate at the plastic hinge positions and hence, when a frame is deflected laterally in the post-elastic range, the required curvature ductility factor at the plastic hinges is greater than the lateral displacement ductility factor of the structure.

Prof. Park pointed out that the plastic hinges should form in beams (beam sidesway mechanism), because the required curvature ductility is more easily obtainable there and the requirements are not so high. Several moment-curvature curves of the flexural prestressed concrete member with various mechanical percentage of prestressing steel, which is concentrated near the tension fiber, are shown in Fig. 3. These curves were prepared on the basis of the rectangular parabola stress-strain curve for the concrete and the actual stress-strain diagram for the prestressing seven wires strand.

The ratio of ultimate curvature to that corresponding to the decompression state at the level of the tendon, can be a measure of the available ductility of a prestressed concrete section. The relationships between the mechanical percentage of prestressing steel and the ductility of the section can be given in Table 1.

An increase in the mechanical percentage of prestressing steel increases the neutral axis depth, and hence reduces the ductility of a section. An increase in the steel prestress reduces the ductility slightly. In general, the rotational ductility demanded of the connecting girders will be anywhere from three to five times that of the required translational ductility. If the translational ductility demanded of a structure is four, the rotational ductility of the member must be greater than 16 .

Considering the available ductility of prestressed concrete sections and the required ductility of structures for seismic design, the mechanical percentage of steel in a prestressed concrete flexural member was thought to be kept less than 0.2 , for safety.

The mechanical percentage of steel could be increased slightly than 0.2 , to avoid excessive increase in the dimensions of member, provided that the designer makes specific calculations of the ductility required and ensures sufficient ductility of members. 
TAELE 1.

\begin{tabular}{|l|c|c|c|c|c|c|}
\hline Mechanical Percentage & 0.10 & 0.15 & 0.20 & 0.25 & 0.30 & 0.35 \\
\hline Ductility of section & 60 & 28 & 16 & 11 & 8 & 6 \\
\hline
\end{tabular}

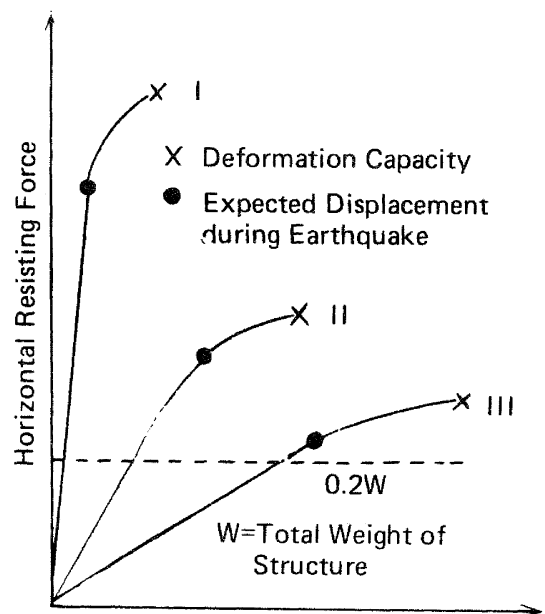

Horizontal Displacement

FIGURE 1

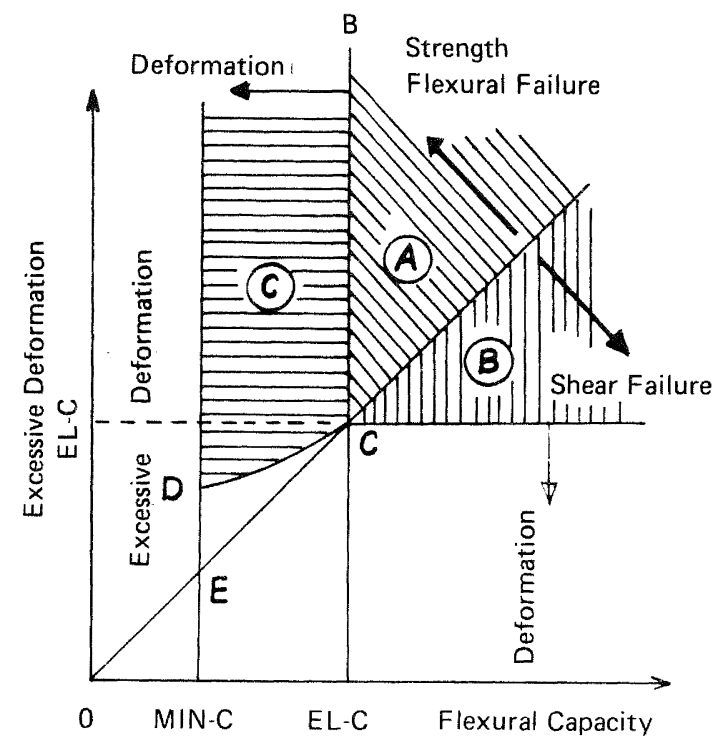

FIGURE 2

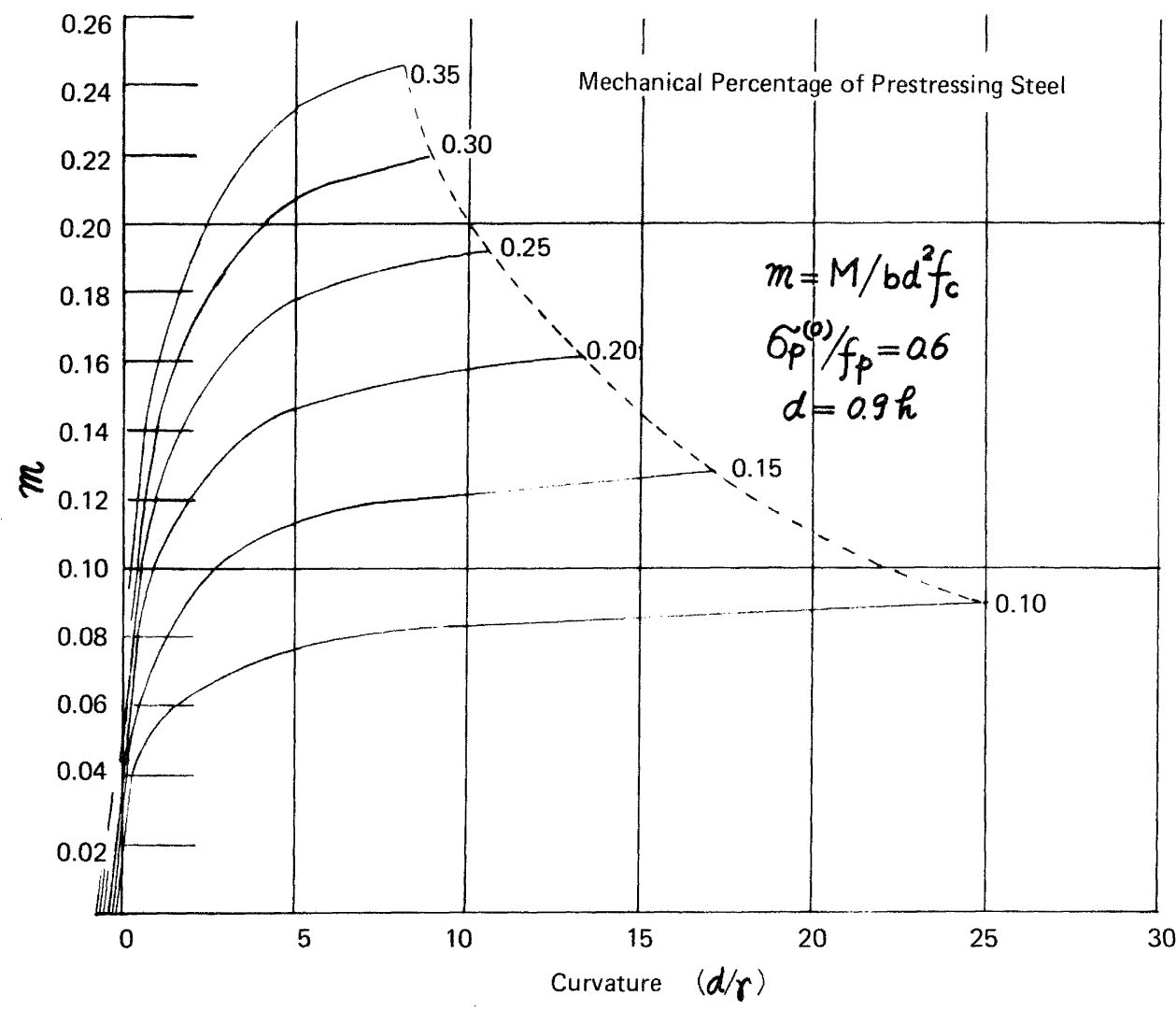

FIGURE 3 